\section{Priming Dusty Miller Seeds: Role of Aeration, Temperature, and Relative Humidity}

\author{
William J. Carpenter \\ Ornamental Horticulture Department, IFAS, University of Florida, \\ Gainesville, FL 32611
}

Additional index words. Senecio cineraria, primed seed dehydration, seed storage, seed germination temperature

\begin{abstract}
Priming permits seeds to slowly imbibe water at regulated rates and to begin the initial stages of germination. Hypertonic polyethylene glycol (PEG) 8000 solutions of 1.0 and 1.2 MPa at 15C improved seed germination of dusty miller (Senecio cineraria DC.). At 0.8 MPa, germination was promoted during priming. No differences in rates, span, or total germination were found among seeds primed for 1, 2, or 3 weeks with or without aeration during priming. Germination percentages of primed and nonprimed seeds were similar at $10,15,20$, and $25 \mathrm{C}$, but $42 \%$ to $81 \%$ higher for primed seed at 30 or 35C. Priming reduced days to $50 \%$ of total germination $\left(T_{50}\right) 23 \%$ to $61 \%$, and germination spans in days $30 \%$ to $67 \%$. Primed seeds germinated most rapidly and uniformly at 20 and $25 \mathrm{C}$. No change in total germination, $T_{50}$, or germination span resulted when moisture contents of primed seeds were lowered to $7.8 \%$ or seeds were held at $\mathbf{- 8 0 C}$ for 7 days. Primed seed performance was unchanged after storage at $5 \mathrm{C}$ and $52 \% \mathrm{RH}$ for 16 weeks.
\end{abstract}

Delayed germination and seedling emergence result in nonuniform plant stands. Currah et al. (1974) found $50 \%$ to $80 \%$ of lettuce (Lactuca sativa L.) head weight variation resulted from time of seedling emergence. The natural germination variability occurring within bedding plant cultivars determines the uniformity of seedling emergence and plant size (Simmonds, 1980). Seed

Received for publication 21 Nov. 1988. Florida Agricultural Experiment Station Journal Series no. 9474. The cost of publishing this paper was defrayed in part by the payment of page charges. Under postal regulations, this paper therefore must be hereby marked advertisement solely to indicate this fact.
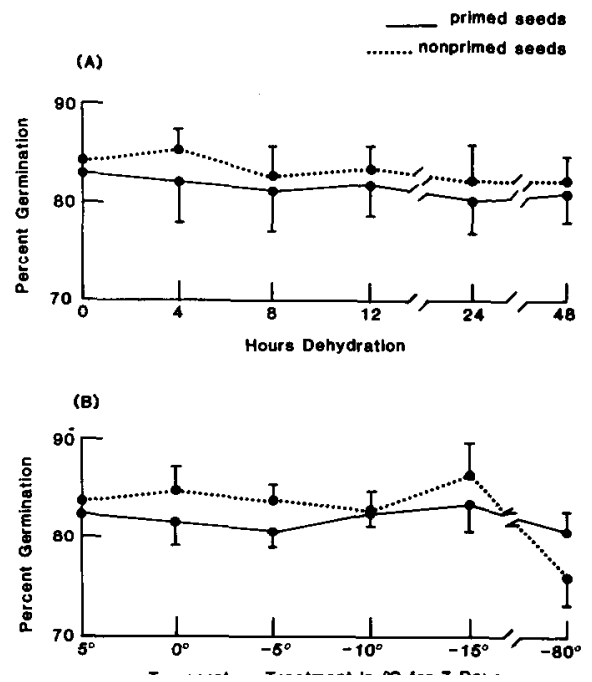

Fig. 1. Primed seed germination after (A) dehydration for 0 to $48 \mathrm{hr}$ and (B) cold temperature treatment at 5 to $-80 \mathrm{C}$ for 7 days. Data points in each study are the means of four replications of 100 seeds.

commercially produced in greenhouses as an annual bedding plant. Direct-seeding dusty miller in propagation flats causes irregular germination at recommended temperatures and seed thermodormancy above $25 \mathrm{C}$. The objectives of these experiments were to develop recommendations for priming dusty miller seeds, to determine if priming overcomes seed thermodormancy, and to measure the response to priming after storage at varying relative humidity levels.

Dusty miller seeds were primed in darkness at $15 \mathrm{C}$ in aerated PEG 8000 solutions at $0.8,1.0$, or $1.2 \mathrm{MPa}$ for $0,1,2$, or 3 weeks. The water potential of the PEG solutions were measured at $15 \mathrm{C}$ with a Wescor vapor pressure osmometer (Wescor, Logan, Utah). Seeds were placed in 80-ml test tubes with $20 \mathrm{ml}$ of PEG solution per $0.1 \mathrm{~g}$ of seed. After priming, seeds were washed with 
Table 1. Comparison of PEG 8000 concentration and period of seed priming at $15 \mathrm{C}$ on dusty miller germination.

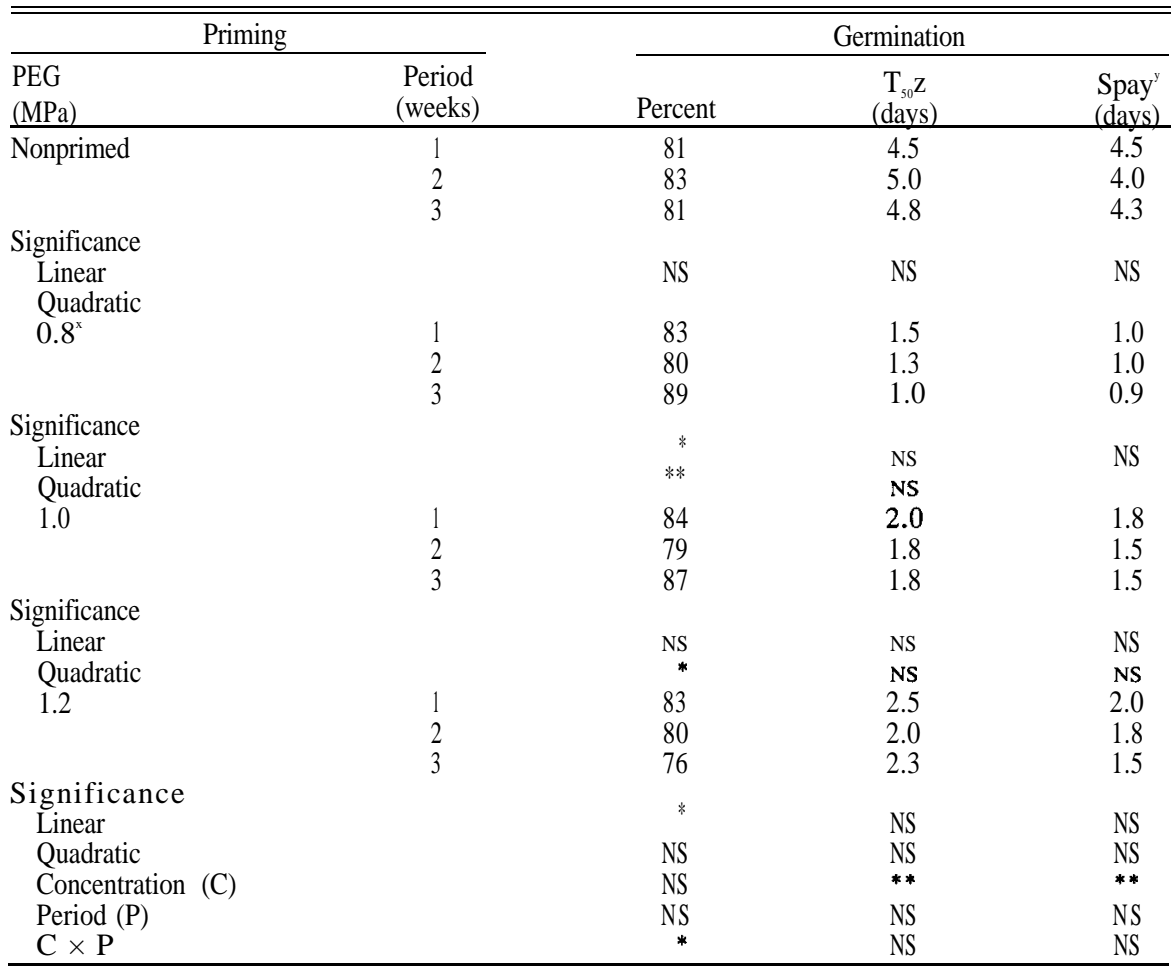

${ }^{2}$ Mean days to $50 \%$ germination.

'Days from $10 \%$ to $90 \%$ germination.

"Data for this treatment included seeds that germinated during the priming treatment.

Ns.****Nonsignificant or significant at $P=0.05$ or 0.01 , respectively. Data are means of 400 seeds.

Table 2. Dusty miller germination comparing seeds aerated and nonaerated during priming with nonprimed seeds.

\begin{tabular}{|c|c|c|c|c|}
\hline \multirow[b]{2}{*}{$\begin{array}{c}\text { Seed } \\
\text { treatment }\end{array}$} & \multirow{2}{*}{$\begin{array}{c}\text { Germination } \\
\text { temp } \\
\text { (C) }\end{array}$} & \multicolumn{3}{|c|}{ Germination } \\
\hline & & Percent & $\begin{array}{r}\mathrm{T}_{50} \mathrm{Z} \\
\text { (days) }\end{array}$ & $\begin{array}{l}\text { Span } \\
\text { (days) }\end{array}$ \\
\hline \multirow[t]{6}{*}{ Nonprimed } & 10 & 80 & 11.6 & 6.8 \\
\hline & 15 & 83 & 6.5 & 5.0 \\
\hline & 20 & 89 & 5.1 & 4.5 \\
\hline & 25 & 78 & 5.4 & 4.3 \\
\hline & 30 & 35 & 6.3 & 5.8 \\
\hline & 35 & 16 & 8.2 & 6.3 \\
\hline \multicolumn{2}{|l|}{ Significance } & * & & \\
\hline \multicolumn{2}{|l|}{ Linear } & $\begin{array}{l}* * \\
* *\end{array}$ & $\begin{array}{l}* * \\
* *\end{array}$ & NS \\
\hline \multicolumn{2}{|l|}{ Quadratic } & $* *$ & $* *$ & \\
\hline \multirow[t]{6}{*}{ Primed aerated } & 10 & 80 & 5.5 & 3.8 \\
\hline & 15 & 86 & 3.2 & 2.5 \\
\hline & 20 & 86 & 2.0 & 1.8 \\
\hline & 25 & 82 & 2.1 & 2.0 \\
\hline & 30 & 65 & 4.4 & 3.3 \\
\hline & 35 & 59 & 6.3 & 4.5 \\
\hline \multicolumn{5}{|l|}{ Significance } \\
\hline \multicolumn{2}{|l|}{ Linear } & ${ }^{* *}$ & $*^{* *}$ & *** \\
\hline \multicolumn{2}{|l|}{ Quadratic } & *** & $* *$ & ** \\
\hline \multirow[t]{6}{*}{ Primed nonaerated } & 10 & 79 & 6.1 & 4.0 \\
\hline & 15 & 80 & 2.6 & 2.3 \\
\hline & 20 & 84 & 2.1 & 1.5 \\
\hline & 25 & 80 & 2.3 & 1.8 \\
\hline & 30 & 76 & 3.9 & 3.0 \\
\hline & 35 & 65 & 5.8 & 4.3 \\
\hline \multicolumn{5}{|l|}{ Significance } \\
\hline \multicolumn{2}{|l|}{ Linear } & $* *$ & NS & NS \\
\hline \multicolumn{2}{|l|}{ Quadratic } & $\begin{array}{l}* * \\
* *\end{array}$ & 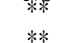 & 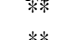 \\
\hline \multicolumn{2}{|l|}{ Treatment $(\mathrm{T})$} & $\begin{array}{l}* * \\
* *\end{array}$ & $\begin{array}{l}* * \\
* *\end{array}$ & $\begin{array}{l}* * \\
* *\end{array}$ \\
\hline \multicolumn{2}{|l|}{ Temperature (TE) } & * & +4 & *** \\
\hline $\mathrm{T} \times \mathrm{TE}$ & & $* *$ & $* *$ & \\
\hline
\end{tabular}

${ }^{2}$ Mean days to $50 \%$ germination.

'Days from $10 \%$ to $90 \%$ germination.

NS, $* * *$ Nonsignificant or significant at $P=0.05$ or 0.01 , respectively. Data are means of 400 seeds.
$100 \mathrm{ml}$ of distilled water (dw), surface moisture was removed by 5 min of vacuum aspiration, and they then were stored at $5 \mathrm{C}$ and $45 \%$ RH 4 days before germination. Treatments contained four 100-seed replicates. Seeds were germinated at 20C in 9-cm petri dishes on two layers of Whatman No. 1 filter paper wetted With $5 \mathrm{ml}$ of dw. Germination counts were made daily. Germination was defined as seeds with visible radicle protrusion through the testa. Treatment means in days to $50 \%$ of final germination $\left(\mathrm{T}_{50}\right)$ and span of germination (days between $10 \%$ and $90 \%$ germination) were calculated as recommended by Furutani et al. (1985). The experiment was a randomized complete block designed as a $4 \times 3$ factorial, with data analyzed by an analysis of variance (ANOVA) and multiple regression analysis.

A second study compared the germination of seeds primed with or without aeration of the 1.0 MPa PEG 8000 osmoticum. Seeds were primed 1 week in aerated PEG solutions in 80-ml test tubes or immersed in 25 $\mathrm{ml}$ of nonaerated solutions in sealed $9-\mathrm{cm}$ petri dishes. Following priming, all seeds were washed, surface dried, and stored as previously described. Treatments consisting of four 100 -seed replications of primed or nonprimed seeds were germinated as described above at a constant 10, 15, 20,25, 30, or $35 \mathrm{C}$. Germination counts, $\mathrm{T}_{50}$, and spans of germination were calculated. The experiment was a randomized complete block designed as a $3 \times 6$ factorial with analyses as in the previous study.

Primed and nonprimed seed germination were determined after reducing seed moisture contents. Seeds primed 1 week at $15 \mathrm{C}$ in nonaerated 1.0 MPa PEG osmoticum were washed, dried, stored 5 days at $5 \mathrm{C}$ and $45 \%$ $\mathrm{RH}$, and weighed. The four 100 -seed replications comprising each treatment were placed in open 9-cm petri dishes and dehydrated for $0,4,8,12,24$, or $48 \mathrm{hr}$ in $35 \mathrm{C}$ forced draft incubators. Treatment replications were reweighed and immediately sealed in screwcapped 4-ml glass vials, 100 seeds per vial, and stored at $5 \mathrm{C}$ for 8 weeks. Seeds were reweighed after storage and germinated in petri dishes at 20C as previously described. Seeds with radicle emergence were counted daily. Total moisture contents of both primed and nonprimed seeds were determined by weighing before and after desiccation at $105 \mathrm{C}$ for $48 \mathrm{hr}$. The experimental design was a 2 $\times 6$ factorial.

Low-temperature effects on primed seed also were evaluated. Seeds primed in nonaerated 1.0 MPa osmoticum of PEG 8000 at $15 \mathrm{C}$ for 1 week were weighed after washing and surface moisture was removed by $30 \mathrm{~min}$ of vacuum aspiration. Treatments of four 100seed replications were placed in $15 \times 2.5$ $\mathrm{cm}$ petri dishes on wire screens supported by segments of tubing $1 \mathrm{~cm}$ above a chemical desiccant. A constant $11 \%$ RH was maintained in the sealed petri dishes by adding $50 \mathrm{ml}$ of saturated lithium chloride to the bottom of each dish (Copeland, 1976). The incubator was held at 5C during the week of seed dehydration. Following dehydration, 
Table 3. Relative humidity level during $5 \mathrm{C}$ storage influences primed dusty miller seed germination.

\begin{tabular}{|c|c|c|c|c|}
\hline \multicolumn{2}{|c|}{ Seed storage } & \multicolumn{3}{|c|}{ Germination } \\
\hline $\begin{array}{l}\text { Period } \\
\text { (weeks) }\end{array}$ & $\begin{array}{l}\text { RH } \\
(\%)\end{array}$ & Percent & $\begin{array}{c}\mathrm{T}_{50} \mathrm{Z} \\
\text { (days) }\end{array}$ & $\begin{array}{l}\text { Span }^{y} \\
\text { (days) }\end{array}$ \\
\hline 0 & & 81 & 2.3 & 1.8 \\
\hline \multirow[t]{4}{*}{2} & 11 & 78 & 2.5 & 2.3 \\
\hline & 52 & 80 & 2.3 & 1.8 \\
\hline & 75 & 79 & 2.0 & 1.5 \\
\hline & 95 & 84 & 2.0 & 1.8 \\
\hline \multicolumn{5}{|l|}{ Significance } \\
\hline Linear & & * & NS & NS \\
\hline Quadratic & & NS & & \\
\hline \multirow[t]{4}{*}{8} & 11 & 83 & 2.8 & 2.5 \\
\hline & 52 & 78 & 2.0 & 1.5 \\
\hline & 75 & 78 & 2.3 & 1.8 \\
\hline & 95 & 66 & 2.3 & 1.5 \\
\hline \multicolumn{5}{|l|}{ Significance } \\
\hline Linear & & & NS & \\
\hline Quadratic & & * & & NS \\
\hline \multirow{4}{*}{16} & 11 & 78 & 2.8 & 2.8 \\
\hline & 52 & 80 & 2.3 & 2.0 \\
\hline & 75 & 72 & 2.8 & 3.0 \\
\hline \multirow{2}{*}{\multicolumn{5}{|c|}{ Significance }} \\
\hline & & & & \\
\hline Linear & & $* *$ & NS & $* * *$ \\
\hline Quadratic & & $* *$ & & *** \\
\hline Weeks(W) & & $\begin{array}{ll}* * * \\
* * *\end{array}$ & $*$ & $\begin{array}{l}* * \\
* *\end{array}$ \\
\hline RH & & $\begin{array}{l}* * \\
* *\end{array}$ & $*$ & $* *$ \\
\hline $\mathrm{W} \times \mathrm{RH}$ & & & " & \\
\hline
\end{tabular}

${ }^{2}$ Mean days to $50 \%$ germination.

'Days from $10 \%$ to $90 \%$ germination.

Ns, $* * *$ Nonsignificant or significant at $P=0.05$ or 0.01 , respectively. Data are the means of 400 seeds.

seeds were weighed, immediately placed in $10-\mathrm{ml}$ sealed glass vials, and immersed and held for 7 days in polyethylene glycol : water $(\mathrm{v} / \mathrm{v})$ in controlled temperature baths (Guy and Carter, 1984) maintained at 5, 0, -5, $-10,-15$, or $-80 \mathrm{C}$. Bath temperatures were lowered $3 \mathrm{C} / \mathrm{hr}$ to final temperatures; after 7 days of storage, seeds were warmed at $4 \mathrm{C} / \mathrm{hr}$ to $5 \mathrm{C}$. Daily germination counts were made as noted earlier. The-experimental design was a $2 \times 6$ factorial.

The relative humidity level during storage of primed seed was evaluated. Seeds primed in nonaerated 1.0 MPa osmoticum of PEG 8000 at $15 \mathrm{C}$ for 1 week were prepared as previously described and stored at $11 \%, 52 \%$, $75 \%$, or $95 \%$ RH for 2,8 , or 16 weeks. Treatments consisted of four 100-seed replications placed in $15 \times 2.5-\mathrm{cm}$ petri dishes on wire screens supported by segments of tubing $1 \mathrm{~cm}$ above chemical desiccants. Differential relative humidity levels were maintained in sealed petri dishes by adding $50 \mathrm{ml}$ of saturated salt solutions as desiccants of known equilibrium values to the bottom of each dish (Copeland, 1976). Incubators maintained a constant $5 \mathrm{C}$ during seed storage. Seeds in treatment replications were weighed before and after storage and germinated tit $20 \mathrm{C}$ in petri dishes as described previously. Daily counts were made of germinated seeds. The experimental design was a $3 \times 4$ factorial with data analyzed using ANOVA and multiple regression analyses.

Total germination was similar for primed and nonprimed seeds for all treatments (Table 1). Germination counts made after terminating priming showed $18 \%, 24 \%$, and
$35 \%$ of seeds primed in $0.8 \mathrm{MPa}$ PEG 8000 for 1,2 , or 3 weeks, respectively, had radicle protrusion. Seeds did not germinate during priming in 1.0 or 1.2 MPa PEG. Primed seeds required significantly fewer days to $T_{50}$ and had shorter spans in days to germination than seeds not primed (Table 1). Seeds primed in $0.8 \mathrm{MPa}$ PEG 8000 required fewer days to germinate, since seeds germinated during priming were included in germination means and spans in Table 1. In subsequent studies, all seed priming was in 1.0 MPa PEG 8000 for 1 week.

Similar total germination resulted at 10 , 15,20 , or $25 \mathrm{C}$ among nonprimed seeds and those with or without aeration during priming (Table 2). Total germination at 30 or $35 \mathrm{C}$ was reduced $6 \%$ to $29 \%$ for primed seed and $42 \%$ to $81 \%$ for nonprimed seed. No differences in germination were found at 30 or $35 \mathrm{C}$ between seeds primed with or without aeration. Khan et al. (1981) reported adequate $\mathrm{O}_{2}$ is required during seed osmoconditioning. Come and Tissaouri (1972) found many seeds fail to germinate after priming in solutions lacking $\mathrm{O}_{2}$. Cantliffe (1981) reported lettuce seeds primed with or without aeration had similar germination percentages, although aeration promoted more rapid and uniform germination.

Primed seeds had $\mathrm{T}_{50}$ and germination span means $23 \%$ to $61 \%$ and $30 \%$ to $67 \%$ shorter, respectively, than nonprimed seeds (Table 2). No differences in $T_{50}$ or germination spans were found between seeds primed with or without aeration. Although total germination, $\mathrm{T}_{50}$, and span of days significantly varied among seed germination temperatures, treatment differences consistently were smaller for primed than nonprimed seeds. Germination percentages were similar for seeds primed with or without aeration, and no differences were found in germination rates or uniformity as reported by Simmonds (1980).

No reductions in total germination occurred when primed or nonprimed seeds were dehydrated for 0 to $48 \mathrm{hr}$ (Fig. 1A). Although primed seed moisture levels declined from $18.1 \%$ to $7.8 \%$ and nonprimed seed moisture levels from $9.9 \%$ to $5.2 \%$, total germination for all treatments only ranged from $83 \%$ to $88 \%$. These results agree with those of Hegarty (1978) that dehydration of seeds following imbibition and before signs of visible germination have no effect on the level or rate of germination on subsequent rehydration. Seed storage for 7 days at $5 \mathrm{C}$ to $-80 \mathrm{C}$ had no effect on primed seed total germination, and nonprimed seed germination was reduced only at $-80 \mathrm{C}$ (Fig. 1B).

The relative humidity level during $5 \mathrm{C}$ primed seed storage influenced total germination, $\mathrm{T}_{50}$, and germination span length following storage. Total germination was reduced after 8 or 16 weeks at $95 \%$ RH seed storage, but not at $11 \%, 52 \%$, or $75 \% \mathrm{RH}$ (Table 3). The $\mathrm{T}_{50}$ and germination spans were lengthened following 8 weeks of seed storage at $11 \% \mathrm{RH}$ and 16 weeks at $11 \%$, $75 \%$, or $95 \%$ RH. Primed seed storage was best at $52 \% \mathrm{RH}$, with no changes in total germination, $\mathrm{T}_{50}$, or germination span during 16 weeks.

These studies show that seed priming improved dusty miller germination. The best osmoticum concentrations were 1.0 or 1.2 $\mathrm{MPa}$, with $0.8 \mathrm{MPa}$ permitting seed germination during priming. Osmoticum aeration was not necessary, which simplified the priming procedure. Primed seed had higher germination than nonprimed only at temperatures $>25 \mathrm{C}$. High temperature seed thermodormancy was reduced by priming, which could permit direct greenhouse seeding during late summer or fall. The reduced days to $\mathrm{T}_{50}$ and shorter germination span after seed priming could improve seedling emergence uniformity and plant stands from greenhouse-sown seeds. Primed dusty miller seed was found to tolerate $-80 \mathrm{C}$ for 1 week or desiccation-reducing seed moisture contents from $18.1 \%$ to $7.8 \%$ without significant germination loss. Primed seeds stored 16 weeks at $52 \% \mathrm{RH}$ and $5 \mathrm{C}$ had no reduction in total germination, increase in days to $\mathrm{T}_{50}$, or longer germination spans after storage. Sixteen weeks storage at $11 \%, 75 \%$, or $95 \%$ RH increased the days to $\mathrm{T}_{50}$ and germination span, and 95\% RH reduced total germination.

Seed priming appears promising as a technique for hastening and increasing total germination and seedling emergence of dusty miller. Direct planting of primed seed in production flats was not evaluated in this study, although the results indicate significant benefits could be achieved. The ease of priming seeds in nonaerated PEG osmoticum should contribute to the adoption of the procedure. Primed seed tolerance of low temperatures, desiccation, and $5 \mathrm{C}$ storage for 4 months at 
$52 \% \mathrm{RH}$ without losing the benefits of priming indicates the likelihood that primed dusty miller seeds can be used commercially.

\section{Literature Cited}

Bradford, K.J. and M. Murray. 1983. Priming tomato seed. Amer. Veg. Grower Aug. p. 1416.

Cantliffe, D.J. 1981. Priming of lettuce seed for early and uniform emergence under conditions of environmental stress. Acta Hort. 122:29-38.

Carpenter, W.J. 1989. Salvia splendens seed pregermination and priming for rapid and uniform plant emergence. J. Amer. Soc. Hort. Sci.
114:247-250.

Come, D. and T. Tissaoui. 1972. Interrelated effects of imbibition, temperature and oxygen on seed germination, p. 157-169. In: W. Heydecker (ed.). Seed ecology. Penn State Univ. Press, University Park.

Copeland, L.O. 1976. Principles of seed science and technology. Burgess, Minneapolis.

Currah, I.E., D. Gray, and T.H. Thomas. 1974 The sowing of germinating vegetable seeds using a fluid drill. Ann. Applied Biol. 76:311-318.

Furutani, S.C., B.H. Zandstra, and H.C. Price. 1985. Low temperature germination of celery seeds for fluid drilling. J. Amer. Soc. Hort. Sci. 110:149-153.
Guy, C.L. and J.V. Carter. 1984. Characterization of partially purified glutathione reductase from cold hardened and nonhardened spinach leaf tissue. Cryobiology 21:454-464.

Hegarty, T.W. 1978. The physiology of seed hydration and dehydration, and the relation between water stress and control of germination. Plant Cell Environ. 1:101-119.

Khan, A.A., A. Szafirowska, and N.H. Peck. 1981. Osmoconditioning of seed. New York's Food and Life Sci. 13:9-13.

Simmonds, J. 1980. Increasing seedling establishment of Impatiens wallerana in response to low temperature or polyethylene glycol seed treatments. Can. J. Plant Sci. 60:561-569. 